4

5

6

7

8

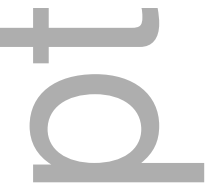

-

Article type : Original Article

7

8

\section{Benchmarks and predictors of coarse woody debris in native forests of eastern Australia}

\section{Abstract}

Fallen coarse woody debris (CWD) is critical to forest biodiversity and function. Few studies model factors that influence CWD availability, Although such investigations are critically needed to inform sustainable forest management. We assess benchmark levels of CWD in unharvested native forests and those harvested for timber, across a range of forests in north-east New South Wales, Australia. We found timber-harvesting was the dominant driver of CWD, with almost double the count (pieces $\left.\mathrm{ha}^{-1}\right)$ and volume $\left(\mathrm{m}^{3} \mathrm{ha}^{-1}\right)$ of total CWD in selectively harvested than unharvested sites. This pattern was consistent across wet and dry forest types. Harvested sites had greater counts of hollow-bearing logs, and greater volumes of small and medium-sized CWD $(15-50 \mathrm{~cm}$ diameter) than unharvested sites. There was no effect of harvesting on the volume of large CWD ( $>51 \mathrm{~cm}$ diameter). Total volumes of CWD (>15cm diameter) varied from 114-166 $\mathrm{m}^{3} \mathrm{ha}^{-1}$. We found few differences in CWD counts and volumes between forest types, with grassy woodlands and forests containing less CWD than other dry and shrubby forest types, reflecting lower potential input rates. The CWD levels recorded here are similar to those recorded in dry and wet sclerophyll forests elsewhere in Australia and are typical of global estimates for 'old growth' forests. Using general linear models we captured up to $57 \%$ of the variation in CWD across sites, and found that timber harvesting, topography and the numbers of standing hollow-bearing and dead trees were significant predictors of CWD. Values for unharvested forest provide a benchmark that could be used to inform retention guidelines for CWD in managed forests in this region. Further assessment of the effect of repeat timber harvesting is needed to fully understand its impact on CWD dynamics, especially if forest residues resulting from timber harvesting are removed from native forests for bioenergy production.

This is the author manuscript accepted for publication and has undergone full peer review but has not been through the copyediting, typesetting, pagination and proofreading process, which may lead to differences between this version and the Version of Record. Please cite this article as doi: $10.1111 /$ aec.12661

This article is protected by copyright. All rights reserved 
Key words: ecological benchmarks; fallen logs; forest biomass; forest residue; sustainable forest management

\section{INTRODUCTION}

Fallen coarse woody debris (CWD) encompasses a variety of woody material, including fallen logs, branches and twigs, stumps, roots and fragments of fallen trees (Woldendorp and Keenan 2005). Because of its many roles, CWD is considered a critical structural and functional feature of many ecosystems (Harmon et al. 1986; Lindenmayer et al. 2002). CWD provides habitat for many components of biodiversity as it provides foraging, nesting/breeding opportunities and regeneration niches (Grove and Meggs 2003; Harmon et al. 1986). CWD also forms an important biogeochemical substrate, providing a key source of nutrients and playing a major role in soil formation (Grove and Meggs 2003; Harmon et al. 1986). Despite its importance, factors influencing the availability of CWD are often overlooked (Bunnell and Houde 2010). However, the maintenance of CWD is crucial for demonstrating ecologically sustainable forest management practices.

Stocks of CWD across the world's forests vary substantially. Factors contributing to CWD inputs, decay and residence time vary across scales and include attributes of the biome, landscape, forest stand and traits of tree species (Burrascano et al. 2013; Harmon et al. 1986). These factors interact with climate, forest type, and natural and human disturbances to influence CWD stocks and attributes (Harmon et al. 1986). Estimates of CWD in forests vary from $5.3 \mathrm{~m}^{3} \mathrm{ha}^{-1}$ in Quercus dominated deciduous broadleaf forests of North America, to $780 \mathrm{~m}^{3} \mathrm{ha}^{-1}$ in Nothofagus and Podocarpus dominated mixed evergreen broadleaf/coniferous forests of South America (Burrascano et al. 2013), and over $1000 \mathrm{~m}^{3} \mathrm{ha}^{-1}$ in the temperate tall wet sclerophyll forests of Tasmania, Australia (Peacock 2009; Woldendorp et al. 2004). Systematic studies conducted in New Zealand and Australia across broad elevation and climate gradients suggest that open forests, in cool climates with slow-growing tree species generally support the greatest estimates of CWD found anywhere in the world (Richardson et al. 2009; Woldendorp and Keenan 2005). However, within any given region other factors such as topographic position (Collins et al. 2012), and dominant tree species (and therefore forest types) impact upon CWD estimates (Harmon et al. 1986; Richardson et al. 2009).

In addition to climate-environment interactions, human disturbances play a significant and sometimes dominant role in determining CWD stocks and composition (Grove and Meggs 2003). Human disturbances include forest management practices such as prescribed fire, silvicultural interventions such as regrowth thinning, and timber harvesting. Fire can create, modify and destroy CWD, through inflicting tree basal injury, leading to increased tree mortality and collapse, or via progressive log consumption, respectively. Studies examining the effects of fire demonstrate that recent wildfire events ( $<3$ years) can decrease CWD stocks (Bassett et al. 2015), as can repeated low intensity prescribed burns, particularly for decayed pieces (Aponte et al. 2014; Stares et al. 2018). Similarly, timber harvesting can increase CWD via practices that retain unmerchantable felled timber in situ 
(Grove 2001; Riffell et al. 2011). The protection of CWD in local unharvested areas can assist in maintaining the amount of CWD at landscape scales (Slade and Law 2017). Understanding how these anthropogenic disturbances influence CWD stocks in comparison to "reference" conditions is important for forest management.

The attributes of CWD within an area vary depending on tree species, tree size at time of death, wood density and decay stage (Grove and Meggs 2003). These factors, among others, play a role in governing the size, decay stage and presence of hollows in CWD (Collins et al. 2012; Williams and Faunt 1997). Differences in CWD type are important to understand, as these attributes impact the utilisation of this resource by forest fauna (Lindenmayer et al. 2002). For example, long pieces of CWD and larger piles of CWD are used preferentially by Napoleon's skink (Egernia napoleonis) in forests of Western Australia (Christie et al. 2013). Large diameter logs also provide greater surface area and substrates for colonisation, in addition to more likely having complex and decayed internal structures, increasing their value to saproxylic and hollow-using fauna (Grove and Meggs 2003; Grove and Forster 2011). Heilmann-Clausen and Christensen (2004) suggest that the full spectrum of CWD sizes are important for different aspects of fungal diversity.

To implement sustainable forest management practices, it is critical to understand the stocks and composition of CWD in managed areas in comparison to "reference" (or unharvested) conditions. Such understanding is becoming increasingly important, as the removal of woody material from postharvest forest residue in managed native forests has gained renewed interest as a way of meeting increased energy needs. In Australia, burning native forest residue to produce electricity is eligible for renewable energy credits under the Renewable Energy Target (RET) Programme (Australian Government 2015). Much uncertainty exists as to the impact of the removal of forest harvest residues on forest ecosystems (Riffell et al. 2011). Although interest in understanding CWD dynamics has increased in Australia (Woldendorp and Keenan 2005), large-scale inventories of CWD stocks across a range of Australian forest types are still needed, in addition to examination of the factors that best predict CWD stocks.

In this study, we assess the stocks and attributes of CWD across a range of wet and dry temperate native forests of eastern Australia to help inform forest management practices. We use datasets collected from forests covering over 50000 ha in northern New South Wales (NSW) to describe benchmark levels of CWD occurring in forests over extensive productivity, elevation and management gradients. We explore environmental variables that best explain CWD stocks (volumes and abundance) and type (decay stage and size class) and hypothesise that variables describing human disturbances (timber harvesting) drive CWD more than natural factors (topography, wildfire, stand characteristics), and that this influence is consistent across a range of forest types. We then compare the CWD estimates from this study area to other areas across Australia, in an effort to develop suitable benchmark estimates of CWD levels in managed forests. 
114 To study a characteristic suite of forested vegetation types we used two regional scale data sets 115 collected in north-eastern New South Wales (NSW), south-eastern Australia hereafter referred to as 116 dataset one: escarpment and tableland forests dataset (Dorrigo region); and dataset two: coastal lowlands and dissected ranges forests dataset (Clarence River catchment).

\section{Dataset 1: Escarpment and tableland forests, Dorrigo region}

This data set sampled a region of approximately 25000 ha supporting extensive Eucalyptus forests and areas of rainforest throughout the Dorrigo and Guy Fawkes plateaux on the eastern edge of the New England Tableland, varying between 200-1200 m above sea level (ASL). Within this area, a sampling strategy was implemented that focussed on harvested and unharvested examples of typical forest types across a range of slopes and elevations. The typical forest types were defined by characteristic dominant canopy species (Forestry Commission of NSW 1989) including blackbutt (Eucalyptus pilularis), tallowood (E. microcorys), Sydney blue gum (E. saligna), grey gum ( $E$. propinqua), broad leaved stringybark (E. caliginosa), spotted gum (Corymbia variegate), grey ironbark (E. siderophloia) and New England blackbutt (E. andrewsii). Rainforest was not subject to systematic sampling.

These forests of the Dorrigo region have been subject to timber harvest since the mid 1800's where practices used, tree species targeted and level of timber removal have varied greatly. Harvesting practices during the early 1900's were generally less intense than those practices in the 1980's, when improved access and technology allowed for extraction of much greater timber yields (Sinclair Knight 1992). Prior to 1930, harvesting focussed on red cedar, coachwood and hoop pine in rainforests, and by the 1940's the focus had shifted to routine selective harvest of hardwood (Eucalyptus) for sawlogs, including repeat harvesting in the 1960's. Timber harvest activities remained intensive into the 1990's, where some plots in the study were subject to harvest in the year prior to data collection (Daly and Hoye 2016; Forestry Commission of NSW 1985; Sinclair Knight 1992). Other disturbances included prescribed burning to manage fuel hazard, and firewood collection. Sections of the study area are also leased to cattle graziers which permitted the lessee to periodically burn parts of their lease hold to regenerate grassy forage for cattle grazing (Sinclair Knight 1992).

\section{Survey stratification}

Seventy-nine transects were established, 50 in harvested areas, and 29 were in unharvested areas. Transects were $500 \mathrm{~m}$ long and $100 \mathrm{~m}$ wide, segmented into five $100 \mathrm{~m}$ by $100 \mathrm{~m}$ sub-plots, where habitat attributes were measured following the methods described below (Sinclair Knight 1992).

Measurement of coarse woody debris and other environmental variables transect (fixed area transect) were measured (full plot description in Countrywide Ecological Services 1995). Logs were defined as any piece of fallen wood greater than $30 \mathrm{~cm}$ in mid-point diameter and 
more than $5 \mathrm{~m}$ long. Logs were tallied according to whether they contained a hollow or not (where a cavity in the heartwood was considered a hollow). Hollow-bearing logs were further categorised as those with hollows greater or less than an opening diameter of $30 \mathrm{~cm}$. Fallen tree heads/canopy branches and collapsed shells were also tallied, where fallen heads from both harvest operations and natural causes were combined. The counts of logs from each category were summed across each sub-plot to calculate the number of logs per transect ( $500 \mathrm{~m}$ by $50 \mathrm{~m}$, or $25000 \mathrm{~m}^{2}$ ), which was then scaled to calculate logs per ha.

Environmental variables were also assessed in the field for each transect including harvest intensity, fire intensity and time since fire, slope, topographic position, forest type, and density of trees $(>10 \mathrm{~cm}$ $\mathrm{DBH}$; divided into all trees, hollow-bearing trees and dead trees) and cut stumps. Harvest intensity was recorded as: no harvest; light; moderate; or severe harvest activities. Intensity was assessed in the field by counting the number of cut stumps present and the level of canopy removal. Intensity was validated with reference to forest management records. Fire intensity was recorded in semiquantitative classes as none; light; moderate; or severe fire events. Time since fire and intensity was assessed in the field at the time of survey based on fire scar height (for gum and stringybark trees), size of regenerating trees and shrubs (for species where regeneration was likely to be fire induced), age class distribution of trees, extent of fire scars, and leaf litter depth. Forest type (whether wet or dry) was also considered when determining the fire history of a site, as dry forests were more likely to have experienced lower intensity but more frequent fires than wet forests (Countrywide Ecological Services 1995). Whether fire was prescribed versus wild was not characterized. Time since fire estimates were validated by comparison to available fire history mapping. These and other variables used in subsequent analyses are described further in the supplementary files (Table S1).

\section{Dataset 2: Coastal lowlands and dissected ranges forests, Clarence River catchment}

This data set sampled a region of approximately 25000 ha across two study areas; low productivity 'coastal lowland forests' (Red Rock study area) and high productivity forests on moist 'dissected ranges' (Washpool study area) of the sub-coastal escarpment ranges, north-eastern NSW (RACAC 1995a).The majority of the coastal lowlands (Red Rock ) study area is below $330 \mathrm{~m}$ (ASL) and comprises open forests, where the dominant canopy species in sampled plots included E. pilularis, spotted gum (Corymbia henryi and $C$. variegata), red bloodwood (C. gummifera), rough-barked apple (Angophora floribunda), needlebark stringybark (E. planchoniana), grey ironbark (E. siderophloia) and E. propinqua. In contrast, the high productivity dissected ranges study area (Washpool) varies between 200-1100 m ASL and is dominated by areas of temperate rainforest and moist Eucalyptus forest. Dominant canopy species in the sampled plots included C. variegate, brushbox (Lophostemon confertus), E. microcorys, and E. saligna. The forests of the Red Rock study area have been subject to a long history of selective hardwood harvesting for poles and sawlogs since 1920. Silviculture practices employed up until the 1940's included ringbarking and thinning, in addition to reject tree felling that occurred in the 1950's and 60's (RACAC 1995a). In the 1970's and 1980's harvesting concentrated on removal of mature, over-mature and defective trees to release the growth potential of 
younger suppressed trees (Forestry Commission of NSW 1987). Sections of this study area were leased to graziers, who also periodically burnt sections of the area, in addition to other hazard reduction burns and wild fires that occurred throughout. The forests of the Washpool study area are more remote and less disturbed, with only one part of the study area having been subject to selective hardwood harvesting that commenced in the 1960's-70's. Parts of this study area adjacent to pastoral land have been subject to frequent low intensity fires, while other sections experience less frequent, but more intense fires.

\section{Survey stratification}

Plots $(n=148)$ were stratified by forest type, growth stage and disturbance (including harvest, fire and grazing disturbances) (RACAC 1995b). Up to four plots were randomly placed within each strata (Red Rock $=100$ plots and Washpool $=48$ plots) (RACAC 1995b). Twenty-one of the Red Rock plots and 18 of the Washpool plots were unharvested, while the remaining had evidence of harvest. Nested rectangular plots were established with a smaller plot located within a larger plot, which was designed to capture the variation in stem density and stem size present in harvested areas (RACAC 1995b). The largest plots established in the Red Rock area were $50 \mathrm{~m} \times 50 \mathrm{~m}$, and in the Washpool area were $100 \mathrm{~m} \times 50 \mathrm{~m}$. Larger plots were used in Washpool because initial sampling suggested that a $50 \mathrm{~m} \times$ $50 \mathrm{~m}$ plot was inadequate to capture sufficient numbers of large hollow bearing trees, especially in unharvested areas (RACAC 1995b).

\section{Measurement of coarse woody debris and other environmental variables}

Data on CWD was collected along a $100 \mathrm{~m}$ transect located centrally across each plot in both study areas. This method was adapted from the line intercept method described by Van Wagner (1968). Logs were defined as any piece of fallen wood $>15 \mathrm{~cm}$ in diameter, of any length. Any log that intercepted the transect was counted, and the degree of hollowing, decay and charring recorded (Table S1). Using these data the volume $\left(\mathrm{m}^{3} \mathrm{ha}^{-1}\right.$ ) of all logs, and hollow logs (with 10-90\% stem hollowing, Table S1) were derived following Van Wagner (1968).

Environmental variables were also assessed per plot including harvest intensity, fire intensity and time since fire, slope, topographic position, forest type, and density of trees $(>20 \mathrm{~cm} \mathrm{DBH}$; divided into all trees, hollow-bearing trees and dead trees) and cut stumps (Table S1), as detailed in RACAC (1995b). Harvest intensity was recorded as: no harvest; Light $=1$ to 3 tree heads in plot; or Heavy = > 3 tree heads/reject logs or $5 \%$ cover of log dump refuse. Fire intensity was recorded as: none; low (ground layer burnt only); moderate (shrub layer burnt); hot (mid stratum burnt); or severe (tree overstorey burnt) fire events. Intensity and time since fire was assessed in the field at the time of survey based on fire scar height, size of regenerating trees and shrubs (including assessment of species that re-sprout versus obligate seeders), mortality and extent of charring of trees and shrubs relative to their size, CWD levels, fire sensitivity of species present and which stratum was burnt. Time since fire estimates were based on the 'best' estimates of the year of the most recent fire, and were subsequently validated by comparison to fire history mapping. 
We analysed CWD data in two stages. We firstly assessed the variation in CWD availability in each dataset (separating the two study areas in dataset 2) by forest type and harvest intensity, closely following the a priori stratification. We secondly modelled variation in CWD using the additional variables measured for each dataset. To allow for comparison between datasets, we assigned each transect or plot to a standardised vegetation formation (Keith formation) using the Comprehensive Regional Assessment Aerial Photographic Interpretation (CRAFTI) vegetation data layer (NPWS 2001), in a Geographic Information System (GIS; ArcMap Version 10.2.2). For Dorrigo data (dataset 1), counts and not dimensions of CWD pieces were recorded, hence only count of CWD per ha could be calculated, not volume. For the Red Rock and Washpool data (dataset 2), log diameters were recorded and hence we calculated CWD volume $\left(\mathrm{m}^{3} \mathrm{ha}^{-1}\right)$, following Van Wagner (1968). We also calculated volume in the following size classes for this dataset: $15-30 \mathrm{~cm} ; 31-50 \mathrm{~cm}$; and $>51 \mathrm{~cm}$ diameter. CWD count per ha could not be calculated for this dataset as it used the line intercept method, which precludes calculation of count on a per ha basis.

\section{Count and volume of logs across forest types and harvest intensities}

250 In our first analysis we assessed the effect of forest type on total count of CWD (Dorrigo) and volume (Red Rock and Washpool study areas analysed separately) using a one-way analysis of variance, and a post-hoc Tukeys HSD tests. Some forest types were under-sampled, and hence we only included forest types that were represented by more than three transects or plots, which led to the exclusion of two forest types in the escarpment and tableland forests (Dorrigo, dataset 1), and the exclusion of one forest type in the dissected ranges forests (Washpool, dataset 2) (see Table 1). We then assessed the effect of harvest intensity on: 1) total CWD count and volume; 2) hollow/decay status (non-hollow bearing logs, hollow-bearing logs, collapsed shells, or tree heads and branches); and size class $(15-30 \mathrm{~cm} ; 31-50 \mathrm{~cm}$ and $>51 \mathrm{~cm}$ diameter, for dataset 2 only). For both datasets, we square root transformed CWD count and volume data (total; non-hollow and hollow count and volume data; $15-30 \mathrm{~cm}$ and $31-50 \mathrm{~cm}$ size classes) to meet the assumptions of normality after inspection of plots. In instances where assumptions could not be met, we used Kruskal-Wallis tests.

\section{Environmental predictors of log count and volume}

We modelled the effect of a suite of environmental predictors (Table S1) on total and hollow-bearing log count and volume using linear models using a normal distribution. There was insufficient data on collapsed shells and heads/branches to warrant further investigation. We selected variables for inclusion based on the findings of Harmon et al. (1986) and Collins et al. (2012), and our knowledge of factors influencing CWD stocks in Australian forests. Skewed variables were log or square root transformed prior to analysis to meet assumptions of normality, and all continuous predictor variables were standardised to have a mean of zero and standard deviation of one. All statistical analyses were conducted using 'R', version 3.2.0 (http://www.r-project.org/). Visual inspections of residual plots confirmed data were normally distributed with homogeneous variances. Exploratory analysis revealed 
that harvest intensity and number of cut stumps (Dorrigo) and basal area (Red Rock and Washpool) were highly positively correlated. Because of this, and our interest in understanding the drivers of CWD stocks in harvested areas specifically, we chose to implement a two-stage modelling approach, as described below. In the first stage of modelling, we investigated relationships between environmental drivers listed in Table S1 and log count and volume. We collapsed harvest intensity to a binary variable to describe sites that had been harvested or not, as a more detailed examination of the effect of harvest intensity (as measured by cut stumps) was undertaken in stage two. We also collapsed data across the Keith formations to three forest types: dry, wet and rainforest (see Table 1). This approach allowed for harvested and unharvested transects and plots to be represented across the three forest types, although rainforest was still under-sampled (Table 1). We did not include time since harvest, as preliminary analysis suggested this variable was correlated with harvest intensity. We ran separate models for the two datasets. Here, we assessed all possible combinations of site characteristics and included an interaction term with the presence of harvest activities. In the coastal lowlands and dissected ranges models (dataset 2), we included a 'site' term that indicated which of the two study areas the data was collected from (Red Rock or Washpool). We only included sites for which we had complete data. This led to models for Dorrigo using $n=69$, and for Red Rock and Washpool using $\mathrm{n}=140$ sites ( 97 and 43 sites, respectively). Where time since fire information was missing, we used the median time since fire for the specific study area (Dorrigo: 5 years; Washpool: 5 years; Red Rock: 3 years). Additionally, there were three transects with no fire history recorded in the Dorrigo area, and as such we assigned these to the light fire history category, as it is likely that these transects had experienced at least some fire in the past.

In the second stage of modelling, we used data for harvested transects and plots only ( $\mathrm{n}=28$ Dorrigo; $\mathrm{n}=104$ Red Rock (76 plots) and Washpool (28 plots)). Here we included all possible combinations of variables listed in Table S1, including cut stumps, as an indicator of harvest intensity. To avoid collinearity in all models, we only included variables that were not strongly collinear (Pearson's correlation coefficient $<0.6$ ). Prior to modelling, we also examined the association between categorical variables using chi square tests. No significant correlation was found between any of our candidate categorical variables, including forest type, topographic position, and harvest intensity $(p>$ 0.05 in all cases), and hence these variables were considered for inclusion in the same models. Further, we calculated the variance inflation factor (VIF) for each variable in each of the 'top' models, and only considered models where the VIF was <2 for all variables (Zuur et al. 2010). We employed an information theoretic approach to identify models with more support by calculating the Akaike Information Criterion corrected for small sample size (AICc), using package MuMIn (Bartoń 2013). We selected our final model for plotting and interpretation based on the lowest AICc, the highest model weight $\left(w_{i}\right)$, and the model with no evidence of co-linearity (as indicated by VIF). Models within two AIC points of the best model were also considered as plausible models. 
314 A total of 5621 logs (> $30 \mathrm{~cm}$ diameter) were sampled during the surveys conducted in the Dorrigo 315 area (dataset 1), of which 1114 were hollow-bearing (19.8\%), and 884 were collapsed and highly 316 decayed (15.7\%). The number of logs recorded per transect ranged from $14-213$, and the number of 317 hollow-bearing logs per transect ranged from $0-55$. On a per hectare basis this equates to an 318 average of $28.6 \pm 1.8$ logs per ha, and $5.7 \pm 0.5$ hollow-bearing logs per ha.

A total of 1266 logs (>15 cm diameter) were sampled in the Red Rock and Washpool areas (dataset 2), of which 455 were hollow-bearing (36\%), and 145 were collapsed and highly decayed (11.5\%). The number of logs recorded per $100 \mathrm{~m}$ transect ranged from $1-28$, of which $0-11$ were hollowbearing. Average volume of logs in the Red Rock sites was $155.5 \pm 12.7 \mathrm{~m}^{3} \mathrm{ha}^{-1}$, where hollowbearing logs had an average volume of $63.4 \pm 6.7 \mathrm{~m}^{3} \mathrm{ha}^{-1}$. Average volume of logs in the Washpool sites was $125.4 \pm 18.9 \mathrm{~m}^{3} \mathrm{ha}^{-1}$, where hollow-bearing logs had an average volume of $77.3 \pm 11.7$ $\mathrm{m}^{3} \mathrm{ha}^{-1}$.

\section{Effect of forest type}

\section{Dataset 1: Escarpment and tablelands (Dorrigo)}

There was no significant effect of forest type on the count of logs per ha in the Dorrigo area $\left(\mathrm{F}_{4,66}=\right.$ $1.02, p=0.403$ ), with the least number of logs recorded in grassy sclerophyll woodland and shrubby dry sclerophyll forest. Both dry and wet forest types contained variable levels of logs (Fig 1a, Table 1).

Dataset 2: Coastal lowlands (Red Rock) and dissected ranges (Washpool)

There was a significant effect of forest type on log volume in the Red Rock area $\left(F_{3,93}=4.02\right.$, $p=0.0097$ ), where grassy dry sclerophyll forest contained significantly lower volumes than dry sclerophyll shrub/grass forest $(p=0.009)$. All other forest types had similar volumes of logs (Fig $1 c$, Table 1). There was a similar volume of logs recorded in rainforest and wet sclerophyll forest in the Washpool area (Fig 1c), however this was not analysed due to a sampling bias towards wet sclerophyll ( $93 \%$ of plots located in this forest type).

\section{Effect of harvest history}

343 Dataset 1: Escarpment and tablelands (Dorrigo)

344 Harvest history had a significant effect on the count of logs (Table 2), where sites with moderate to 345 heavy harvest had up to twice the logs on the ground than sites subject to no or light harvesting (Fig 346 1b). Logs with no hollows made up the greatest proportion of total logs (55\%), and were most 347 abundant in moderately and heavily harvested sites (Fig 1b, Table 2). Hollow logs were significantly 348 more abundant in heavily harvested sites, but no differences were found among the other harvest 349 intensities (Fig 1b, Table 2). Collapsed shells were least abundant in sites with a light harvest history. 350 Heads and branches were found in similar frequency across all harvest intensities, though there was a trend for a greater frequency in moderate and heavy harvest intensities (Fig 1b, Table 2). 
354 Harvest intensity had a significant effect on the volume of logs $\left(\mathrm{m}^{3} \mathrm{ha}^{-1}\right)$ in the Red Rock study area 355 (Table 2), where volumes were greater in sites subject to heavy harvest than unharvested sites (Fig 1d). In the Red Rock area the volume of non hollow-bearing logs was 2.5 times higher in heavily harvested sites than unharvested sites $(p<0.001)$, and was marginally higher than light harvest sites $(p=0.064)$. No difference occurred between sites of no and light harvest. There was no effect of harvest history on the volume of hollow-bearing logs, or collapsed shells (Fig 1d, Table 2). Sites subject to heavy harvest contained significantly greater volumes of smaller CWD $15-30 \mathrm{~cm}$ diameter (Table 2). Sites with light and heavy harvest also contained greater volumes of medium sized CWD $31-50 \mathrm{~cm}$ diameter, in comparison to non-harvested sites (Table 2). There was no effect of harvest history on the volume of large CWD $>51 \mathrm{~cm}$ diameter (Table 2).

There was no significant effect of harvest intensity on the total volume of logs in the Washpool study area, or on the volume of non hollow-bearing, hollow-bearing and collapsed logs (Fig 1d, Table 2), although there was a trend for unharvested areas to contain lower volumes of hollow logs. However, in Washpool there was marginally greater volumes of small and medium sized CWD (15 - 30, and 31 $-50 \mathrm{~cm}$ diameter) recorded in heavily harvested sites in comparison to sites with light or no harvest, but no differences recorded for large CWD $>51 \mathrm{~cm}$ diameter (Table 2).

\section{Environmental predictors of CWD}

Dataset 1: Escarpment and tablelands (Dorrigo)

374 There was a greater number of logs in harvested areas, in areas with a greater time since fire (years), and in areas with a greater number of standing dead trees (Table S2; Fig 2a). Conversely, number of logs decreased with increasing number of standing trees (graph not shown), and hollow-bearing trees. Forest type was also included in this model, although not significant (see Table S3). Number of logs decreased along the topographic gradient, with more logs on ridges than gullies. There was one competing model within two AICc points, which included all of the above variables, and a significant interaction between harvest history and topography, showing that log numbers declined along the topographic gradient in harvested areas (least in gullies), however log numbers were relatively similar across topographies in unharvested areas.

Hollow-bearing logs were best predicted by the same set of variables as above, following similar overall patterns (Table S2). Number of hollow logs increased in sites with greater numbers of hollowbearing trees; while we found the converse to be true for all logs.

When we examined the number of logs in harvested areas separately, only one top model resulted for the number of all logs (Table S2), which increased with time since fire, number of dead trees and the number of cut stumps recorded per transect (Fig 2b). The number of hollow logs was the same (Table S2). The variance explained by these models was moderate to high, with models of all logs explaining up to $57 \%$ of variation, and models of hollow logs explaining up to $36 \%$ (Table S3). 
There was a greater volume of logs $\left(\mathrm{m}^{3}\right.$ ha $\left.{ }^{-1}\right)$ in harvested areas (Table S2; Fig 3a). The total volume of logs decreased with increasing numbers of standing dead and hollow-bearing trees, however the effect of dead trees was weak, and non-significant (Table S2, Fig 3a). In contrast to the Dorrigo region, the volume of logs was greatest in gullies and lowest in ridges.

400

The volume of hollow-bearing logs was greater in harvested areas, and declined in areas with greater numbers of standing hollow-bearing trees (Table S2; Table 3).

403

404

When harvested sites were examined we found the volume of all logs declined in areas with greater densities of all and hollow-bearing trees, was lowest in ridges and upper slopes, and increased with increasing basal area of cut stumps (Table S2; Fig 3b). The top model for the volume of all logs in harvested sites explained $31 \%$ of the variation in log volume, which was substantially more than the other high-ranking models considered in this dataset (Table S3). The volume of hollow-bearing logs in harvested sites was the most poorly predicted response variable considered, where the top model was the null model that contained no variables (Table S2).

411

\section{DISCUSSION}

413 We found that levels of CWD were driven by environmental characteristics and their interaction with 414 timber harvesting. Stand structure was also an important predictor of CWD, where similar patterns were found in harvested and unharvested forests, although its influence differed subtly in the different regions examined. Harvested forests typically contained up to twice the level of CWD as unharvested forest, though this was dominated by smaller size classes of CWD. Our models captured significantly more variation in CWD (up to 57\%) than other studies (e.g. only $3 \%$ variation captured in Richardson et al. 2009), indicating the disturbance history and environmental attributes of sites captured here play a significant role in driving CWD stocks and quality.

\section{Effect of harvest history and stand structure}

423 We found that harvesting generated significant counts and volumes of hollow-bearing and non-hollowbearing CWD across all forests examined. We also found that harvesting generated greater volumes of small and medium-sized CWD (up to $50 \mathrm{~cm}$ diameter), but did not affect volumes of large CWD ( $>51 \mathrm{~cm}$ diameter). The most decayed material (collapsed shells) was equally abundant across harvest intensities, with a similar proportion of collapsed material recorded in both study areas (11 $15 \%$ of all CWD). The relatively stable levels of large and collapsed CWD observed suggests that climatic and other factors influencing decay rates are similar between the two study areas. The generation of different sized CWD by harvesting may have implications for fauna, as different taxa are known to utilise different types of CWD for different purposes (e.g. for sheltering, navigation, foraging, breeding, detailed in Lindenmayer et al. 2002). As such, forest management practices should aim to 
retain CWD of comparable quantity and type as that found in "reference" areas, which would mean prioritising retention of larger CWD and logs with hollows (see below).

Few Australian studies have examined the impact of harvest activities on CWD volume. Of those that have, Grove (2001) recorded lower volumes of CWD in harvested stands versus old growth lowland tropical rainforests in Queensland (29 and $36 \mathrm{~m}^{3} \mathrm{ha}^{-1}$, respectively). Peacock (2009), however, recorded higher CWD volumes and total log lengths in harvested forests compared to mature forests in Tasmania, although trends were variable with CWD volumes up to $1200 \mathrm{~m}^{3} \mathrm{ha}^{-1}$ being recorded depending on the pulpwood ultilisation standards at time of harvest. The positive relationship between timber harvest intensity and CWD levels found here contrasts with many studies from Europe. Recent and intensive silvicultural management ( $<25$ years) in oak and beech forests leads to highly variable CWD levels (Vandekerkhove et al. 2009), and European forests with a long history of intensive timber extraction can have half the CWD levels as compared to unharvested and old growth forests (Ekbom et al. 2006). The forests in our study have a much shorter and less intensive history of eucalypt harvest than in Europe, with the Red Rock area having the longest history of routine harvesting (since 1920), whereas routine harvest of eucalypts did not intensify until the 1960's in the Dorrigo area. Contrasting patterns of CWD response to timber harvest between Australian and European studies may indicate that over time and with increasing and continuous management, CWD stocks in managed forests in Australia may decline, emphasising the need for a better understanding the impact of multiple harvests on this resource across a range of Australian forests (Grove 2009; Grove and Meggs 2003).

Across all forests we consistently found greater count and volume of all CWD in sites with lower numbers of standing hollow-bearing trees. We suggest the number of standing hollow-bearing trees reflects disturbance regimes, including past fire, silvicultural and harvesting treatments that influence standing hollow-tree stock. Indeed, in both study areas there was a negative association between numbers of hollow trees and harvest intensity (Pearson's correlation coefficient tablelands $=-0.2$; coastal lowlands and ranges $=-0.3$ ), which has also been found in previous studies (McLean et al. 2015). We also found numbers of dead trees to have a strong positive association with all and hollowbearing CWD (fallen CWD as measured here) in the tableland forests. Hence, sites with greater numbers of hollow and dead standing trees were likely to be less intensively harvested (due to restrictions on harvest intensity in sites with high 'habitat values'), leading to lower fallen CWD inputs.

\section{Limitations of the datasets}

There are several limitations of the data collected in these studies. Firstly, due to the availability and accessibility of different forest types, they were sampled to differing intensities, which may affect the reliability of CWD estimates within specific forest types. However, across the forests examined we found relatively low variation in log count and volume between forest types. Grassy woodlands and forests contained less CWD than other dry, shrubby forest types presumably reflecting lower potential input rates. There was no significant difference between rainforest, wet and dry forests in either study 
region, however rainforests were under-sampled, and CWD found there would be subject to different accumulation and decay rates when compared to eucalypt forests. Hence, despite different sampling intensities, its effect is unlikely to have influenced our conclusions.

Secondly, fire histories were determined in the field, using several measurements which were combined into relatively simple indices. This, combined with variable associations of fire with particular forest types, may explain why we found inconsistent effects of fire across study areas, and a lack of effect of fire severity. For example, time since fire was important in the tableland forests, where dry forest types made up $52 \%$ of the sampling plots. This forest type experiences more frequent wildfires (Binns 1995) than wet types, and hence it is possible that the importance of time since fire in the models for this region was influenced by the large number of sample plots in this forest type. Conversely, in the coastal lowlands and dissected ranges forests, time since fire had no effect in our models. In these forests there was a similar fire history between the wet and dry forest types, however rainforest did experience significantly longer time since fire, but rainforest and long unburnt sites ( $\geq 20$ years since fire) outside of rainforest were poorly represented in the sampling plots ( $2 \%$ and $5.5 \%$ of plots, respectively). Hence, the similarity in fire histories between the two dominant forest types in this region (wet and dry), and under-sampling of long unburnt plots likely influenced the lack of effect of fire on CWD that we measured. Other Australian studies examining the impact of prescribed fire have found time since fire to be an important driver of CWD in relatively undisturbed dry open forests and woodlands of northern NSW (Croft et al. 2016). In a carefully planned experiment that manipulated low intensity fire frequency in forests of southern NSW, Stares et al. (2018) found fire frequency was of lesser importance than harvest history. Further sampling of different fire severity, at a range of topographic positions would also improve our understanding of fire effects on CWD.

Finally, we also found variable effects of topography across regions, which may also have been influenced by the sampling design. In agreement with other Australian studies (Bassett et al. 2015; Collins et al. 2012), we found log volume was greatest in gullies and declined substantially upslope in the coastal lowlands and dissected ranges in both harvested and unharvested plots. We did not detect this pattern in the tableland forests, where there were greater count of logs in harvested gullies in comparison to upper slopes, however no differences in log counts were found across topography in unharvested areas. This result however may have been influenced by the apparent sampling bias towards upper, mid and lower slopes, with under-sampling in gullies $(n=2)$, and ridges $(n=5)$ in this region.

\section{Comparison of CWD levels to other forest types}

We found averages of $114 \mathrm{~m}^{3} \mathrm{ha}^{-1}$ and $166 \mathrm{~m}^{3} \mathrm{ha}^{-1}$ of all CWD (> $15 \mathrm{~cm}$ diameter) in unharvested and harvested coastal lowlands and ranges forests, respectively. These values are similar to other open wet and dry sclerophyll forests in NSW, where values between 69 to $193 \mathrm{~m}^{3} \mathrm{ha}^{-1}$ have been recorded in selectively harvested areas (Woldendorp et al. 2004). These values are much lower than those 
513 recorded in tall, cool temperate wet forests of Tasmania, where values up to $1614 \mathrm{~m}^{3} \mathrm{ha}^{-1}$ have been

514 recorded (Woldendorp et al. 2004), but much higher than studies of woodland systems (e.g. $0-52 \mathrm{~m}^{3}$

$515 \mathrm{ha}^{-1}$ recorded by McElhinny et al. 2006), or drier and less productive eucalypt dominated forests (e.g.

$51656 \mathrm{~m}^{3} \mathrm{ha}^{-1}$ recorded by Croft et al. 2016). The mean volume found here is less than the global median

517 reported for old-growth moist temperate forests $\left(151 \mathrm{~m}^{3} \mathrm{ha}^{-1}\right)$, possibly reflecting the different

518 dynamics within Australian eucalypt forests or faster decay rates in a warmer climate at lower

519 latitudes.

520

521 In terms of CWD density (pieces ha ${ }^{-1}$ ), we found higher counts in harvested than unharvested areas

522 (average 39 and 22 large logs ha $^{-1}$, respectively). Peacock (2008) recorded higher CWD count

523 (pieces $>10 \mathrm{~cm}$ diameter) in harvested forests compared to similar unharvested or mature forests in

524 East Gippsland Victoria, although this trend was not apparent if CWD was measured using total

525 length or attributes such as relative decay class. Similarly, Law et al. (2013) recorded 230 pieces of

526 logs (> $10 \mathrm{~cm} \mathrm{DBH})$ per ha in regrowth vs 107 per ha in unharvested dry sclerophyll forests in NSW.

527 Differences in absolute values recorded per ha can be attributed to differences in the minimum size of

528 CWD measured, in addition to decomposition rates, dominant canopy species and site disturbances.

529

530 Recommendations for the management of CWD

531 CWD represents an important component of forest ecosystems and it is important to manage this

532 resource for ecosystem functioning, forest health and as habitat. Unregulated use of forest biomass

533 for energy production has the potential to impact CWD stocks, however our ability to predict the

534 nature of those impacts and recommend biomass harvest guidelines will depend on developing a

535 better understanding of the nature of forest biomass removal (e.g. log length, diameter and bark

536 component). We recorded 1.5-2 times the count and volume of CWD in harvested areas. However,

537 the count or volume of CWD required to maintain critical ecosystem functions is highly context

538 specific and as a minimum it would be expected that retaining levels similar to unharvested forests is

539 prudent. In the unharvested forests studied, this equates to an average of $114 \mathrm{~m} \mathrm{ha}^{3}$. In comparison,

540 harvested forests supported, on average, an additional $52 \mathrm{~m}^{3} \mathrm{ha}^{-1} \mathrm{CWD}$, which comprised mostly

541 small $\left(15-30 \mathrm{~cm}\right.$ diameter $\left.15.3 \mathrm{~m}^{3} \mathrm{ha}^{-1}\right)$ and medium sized material $\left(31-50 \mathrm{~cm}\right.$ diameter $28.7 \mathrm{~m}^{3} \mathrm{ha}$

$\left.542{ }^{1}\right)$. Additionally, hollow-bearing CWD and fallen logs with larger diameters $(>51 \mathrm{~cm})$ may have a

543 disproportionately important role in the ecosystem, and should be not be targeted during harvesting

544 operations. Further investigations of the effect of repeat harvest cycles on stand and CWD dynamics,

545 patterns of CWD use by fauna and a consideration of the wider local landscape (Slade and Law

546 2017), will assist with development of guidelines for CWD retention during harvest operations.

\section{REFERENCES}

549 Aponte C., Tolhurst K. G. \& Bennett L. T. (2014) Repeated prescribed fires decrease stocks and 550 change attributes of coarse woody debris in a temperate eucalypt forest. Ecol. Appl. 24, 976-89.

551 Australian Government. (2015) Renewable Energy Target (RET) Scheme, Australian Government, 552 Canberra. http://www.environment.gov.au/climate-change/renewable-energy-target-scheme

This article is protected by copyright. All rights reserved 
554 Bassett M., Chia E. K., Leonard S. W., Nimmo D. G., Holland G. J., Ritchie E. G., Clarke M. F. \& 555 Bennett A. F. (2015) The effects of topographic variation and the fire regime on coarse woody debris: 556 insights from a large wildfire. For. Ecol. Manage. 340, 126-34.

557 Binns D. L. (1995) Flora survey, Dorrigo three year environmental impact statement area, Northern 558 Region. New South Wales.

559 Bunnell F. L. \& Houde I. (2010) Down wood and biodiversity - implications to forest practices. Environ. 560 Rev. 18, 397-421.

561 Burrascano S., Keeton W. S., Sabatini F. M. \& Blasi C. (2013) Commonality and variability in the 562 structural attributes of moist temperate old-growth forests: A global review. For. Ecol. Manage. 291, $563 \quad 458-79$.

564 Christie K., Stokes V. L., Craig M. D. \& Hobbs R. J. (2013) Microhabitat Preference of Egernia 565 napoleonis in Undisturbed Jarrah Forest, and Availability and Introduction of Microhabitats to 566 Encourage Colonization of Restored Forest. Restor. Ecol. 21, 722-8.

567 Collins L., Bradstock R. A., Tasker E. M. \& Whelan R. J. (2012) Impact of fire regimes, logging and 568 topography on hollows in fallen logs in eucalypt forest of south eastern Australia. Biol. Conserv. 149, $56923-31$.

570 Countrywide Ecological Services. (1995) Fauna Report. Dorrigo Interim Environmental Impact 571 Statement. Supporting Document No.3. Prepared for State Forests of New South Wales Sydney.

572 Croft P., Hunter J. T. \& Reid N. (2016) Forgotten fauna: Habitat attributes of long-unburnt open 573 forests and woodlands dictate a rethink of fire management theory and practice. For. Ecol. Manage. $574366,166-74$

575 Daly G. \& Hoye G. (2016) Survey of the reptiles of the montane forests near Dorrigo on the north 576 coast of New South Wales. Aust. Zool. 38, 26-42.

577 Ekbom B., Schroeder L. M. \& Larsson S. (2006) Stand specific occurrence of coarse woody debris in 578 a managed boreal forest landscape in central Sweden. For. Ecol. Manage. 221, 2-12.

579 Forestry Commission of NSW. (1985) Management Plan for Dorrigo Management Area. Forestry 580 Commission of NSW Sydney, NSW.

581 Forestry Commission of NSW. (1987) Management Plan for Grafton Management Area. Forestry

582 Commission of NSW Sydney, NSW. 
Grove S. (2009) Coarse woody debris conservation management in the context of fuelwood and firewood harvesting on State forests in Tasmania. Technical Report 17/2009. Division of Forest Research and Development, Forestry Tasmania Hobart, TAS

Grove S. \& Meggs J. (2003) Coarse woody debris, biodiversity and management: a review with particular reference to Tasmanian wet eucalypt forests. Australian Forestry 66, 258-72.

Grove S. J. (2001) Extent and composition of dead wood in Australian lowland tropical rainforest with different management histories. For. Ecol. Manage. 154, 35-53.

Grove S. J. \& Forster L. (2011) A decade of change in the saproxylic beetle fauna of eucalypt logs in the Warra long-term log-decay experiment, Tasmania. 2. Log-size effects, succession, and the functional significance of rare species. Biodivers. Conserv. 20, 2167-88.

Harmon M. E., Franklin J. F., Swanson F. J., Sollins P., Gregory S., Lattin J., Anderson N., Cline S., Aumen N. G. \& Sedell J. (1986) Ecology of coarse woody debris in temperate ecosystems. Adv. Ecol. Res. 15, 133-302.

Heilmann-Clausen J. \& Christensen M. (2004) Does size matter? For. Ecol. Manage. 201, 105-17.

Law B., Chidel M., Britton A. \& Brassil T. (2013) Response of eastern pygmy possums, Cercartetus nanus, to selective logging in New South Wales: home range, habitat selection and den use. Wildl.

\section{Res. 40, 470-81.}

Lindenmayer D., Claridge A., Gilmore A., Michael D. \& Lindenmayer B. D. (2002) The ecological roles of logs in Australian forests and the potential impacts of harvesting intensification on log-using biota. Pac. Conserv. Biol. 8, 121-40.

McElhinny C., Gibbons P. \& Brack C. (2006) An objective and quantitative methodology for constructing an index of stand structural complexity. For. Ecol. Manage. 235, 54-71.

McLean C. M., Bradstock R., Price O. \& Kavanagh R. P. (2015) Tree hollows and forest stand structure in Australian warm temperate Eucalyptus forests are adversely affected by logging more than wildfire. For. Ecol. Manage. 341, 37-44.

Peacock R. J. (2008) Biodiversity surrogates and metrics: their potential for assessing the sustainability of private native forestry. RIRDC Publication No. 08/043. A report for the RIRDC/Land \& Water Australia/FWPRDC/MDBC Joint Venture Agroforestry Program Rural Industries Research and Development Corporation. Kingston, ACT. 69 p.

Peacock R. J. (2009) A Private Native Forestry Metric to Assess Forest Structural Change. Publication No. 09/019 Project No PRJ- 002688 a report for RIRDC Land and Water Australia; FWPRDC; MDBC Joint Venture Agroforestry Program Rural Industries Research and Development Corporation. Kingston, ACT. 35 p. 
617 NSW National Parks and Wildlife Service, State Forests of NSW, Resource and Conservation

618 Assessment Council (RACAC). NSW Government. Sydney, NSW.

RACAC. (1995b) Joint Old Growth Forest Project: Working Papers Volume 3. Field Surveys to indentify old growth forest. NSW National Parks and Wildlife Service, State Forests of NSW, Resource and Conservation Assessment Council (RACAC). NSW Government. Sydney, NSW.

623 W., Griffiths A. D., Wiser S. K. \& Wright E. F. (2009) Deadwood in New Zealand's indigenous forests. 624 For. Ecol. Manage. 258, 2456-66.

625 Riffell S., Verschuyl J., Miller D. \& Wigley T. B. (2011) Biofuel harvests, coarse woody debris, and 626 biodiversity - A meta-analysis. For. Ecol. Manage. 261, 878-87.

627 Sinclair Knight. (1992) Proposed Forestry Operations, Dorrigo Management Area. Environmental 628 Impact Statement. Sydney, NSW.

629 Slade C. \& Law B. (2017) The other half of the coastal State Forest estate in New South Wales; the 630 value of informal forest reserves for conservation. Aust. Zool. 39, 359-70.

Stares M. G., Collins L., Law B. \& French K. (2018) Long-term effect of prescribed burning regimes and logging on coarse woody debris in south-eastern Australia. Forests 9, 242.

Van Wagner C. (1968) The line intersect method in forest fuel sampling. For. Sci. 14, 20-6. takes over from man: Dead wood accumulation in previously managed oak and beech woodlands in North-western and Central Europe. For. Ecol. Manage. 258, 425-35.

637 Williams M. R. \& Faunt K. (1997) Factors affecting the abundance of hollows in logs in jarrah forest of 638 south-western Australia. For. Ecol. Manage. 95, 153-60.

639 Woldendorp G., Keenan R., Barry S. \& Spencer R. (2004) Analysis of sampling methods for coarse 640 woody debris. For. Ecol. Manage. 198, 133-48.

641 Woldendorp G. \& Keenan R. J. (2005) Coarse woody debris in Australian forest ecosystems: a 642 review. Austral Ecol. 30, 834-43.

643 Zuur A., F. , leno E., N. \& Elphick C., S. (2010) A protocol for data exploration to avoid common 644 statistical problems. Methods in Ecology and Evolution 1, 3-14.

\section{SUPPORTING INFORMATION}

This article is protected by copyright. All rights reserved 
647 Supplementary Table 1: Data on CWD and other site characteristics for each study area 648 Supplementary Table 2: Summary from linear model analysis

649 Supplementary Table 3: Summary of 'top' linear models

650

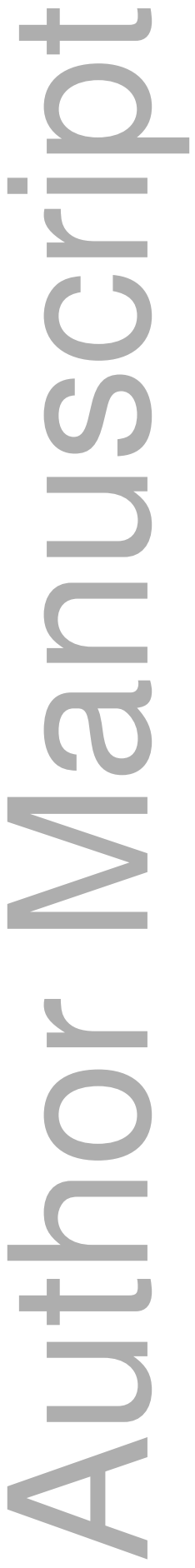

This article is protected by copyright. All rights reserved 
Table 1: Average ( \pm standard error SE) levels of coarse woody debris across forest types, in dataset 1: the escarpment and tableland forests from the Dorrigo area (count of logs per ha $>30 \mathrm{~cm}$ diameter); and, dataset 2: coastal and dissected ranges forests from the Red Rock and Washpool areas, respectively

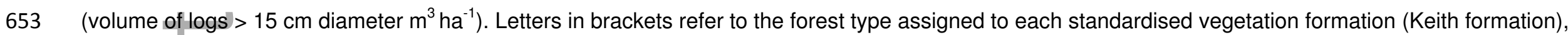

654 used in subsequent modelling ( $D=$ dry forest; $R=$ rainforest, $W=$ wet forest).

\begin{tabular}{|c|c|c|c|c|c|c|c|c|c|c|}
\hline \multirow{3}{*}{ 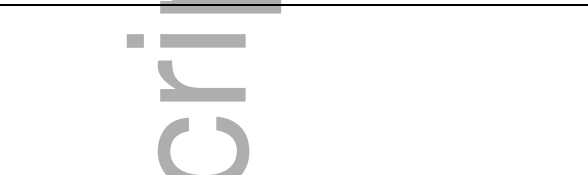 } & \multirow{2}{*}{\multicolumn{2}{|c|}{ No. of plots }} & \multicolumn{4}{|c|}{ All logs } & \multicolumn{4}{|c|}{ Hollow bearing logs } \\
\hline & & & \multicolumn{2}{|c|}{ Unharvested } & \multicolumn{2}{|c|}{ Harvested } & \multicolumn{2}{|c|}{ Unharvested } & \multicolumn{2}{|c|}{ Harvested } \\
\hline & Unharvested & Harvested & Average & SE & Average & SE & Average & SE & Average & SE \\
\hline \multicolumn{11}{|c|}{$\begin{array}{l}\text { Dataset 1: Escarpment and tableland forests (Average count of } \\
\text { logs } \mathrm{ha}^{-1} \text { ) }\end{array}$} \\
\hline Dry sclerophyll shrub/grass forest (D) & 5 & 5 & 20.56 & 2.42 & 47.04 & 7.70 & 7.04 & 1.36 & 11.44 & 2.84 \\
\hline Grassy dry sclerophyll forest (D) & 13 & 11 & 17.08 & 1.64 & 35.38 & 3.92 & 3.05 & 0.71 & 6.69 & 0.79 \\
\hline Rainforest (R) & 5 & 4 & 27.28 & 5.60 & 27.70 & 8.69 & 6.56 & 2.05 & 5.10 & 2.07 \\
\hline${ }^{*}$ Sclerophyll grassy woodland (D) & 2 & 0 & 11.00 & 2.20 & - & - & 1.00 & 0.60 & - & - \\
\hline Semi-mesic grassy forest (W) & 12 & 5 & 26.13 & 4.20 & 46.80 & 11.22 & 5.70 & 1.34 & 7.04 & 1.18 \\
\hline${ }^{*}$ Shrubby dry sclerophyll forest (D) & 4 & 0 & 13.90 & 2.30 & - & - & 2.20 & 0.77 & - & - \\
\hline Wet sclerophyll forest (W) & 6 & 5 & 29.13 & 6.09 & 42.72 & 8.39 & 5.13 & 1.29 & 7.52 & 2.98 \\
\hline \multicolumn{11}{|c|}{ Dataset 2: Coastal lowlands forests (Average volume logs } \\
\hline \multicolumn{11}{|l|}{$\left.m^{3} h a^{-1}\right)$} \\
\hline Dry sclerophyll shrub/grass forest (D) & 1 & 16 & 99.07 & - & 224.89 & 47.24 & 5.44 & - & 92.68 & 24.09 \\
\hline Grassy dry sclerophyll forest (D) & 3 & 23 & 91.27 & 36.55 & 94.68 & 11.98 & 22.46 & 18.66 & 29.61 & 6.02 \\
\hline Shrubby dry sclerophyll forest (D) & 16 & 26 & 107.60 & 18.67 & 202.17 & 24.32 & 54.96 & 11.39 & 80.71 & 11.92 \\
\hline Wet sclerophyll forest (W) & 1 & 11 & 55.52 & - & 186.43 & 40.67 & - & - & 81.10 & 24.89 \\
\hline
\end{tabular}

Dataset 2: Dissected ranges forests (Average volume logs $\left.m^{3} h a^{-1}\right)$

${ }^{*}$ Rainforest $(\mathrm{R})$

2

19.37

189.95

159.11

8.99

20.97

This article is protected by copyright. All rights reserved 
Wet sclerophyll forest (W)

14

26

$\begin{array}{lll}135.02 & 38.82 & 155.43\end{array}$

22.44

47.43

15.56

${ }^{*}$ Not included in 
658 Table 2: Effect of harvest intensity pairwise comparisons. Mod = moderate (Dataset 1). Harvest 659 intensity was scored separately in each dataset, as detailed in Supplementary Table 1.

\begin{tabular}{|c|c|c|c|}
\hline Response & F-value & p-value & Tukeys HSD \\
\hline \multicolumn{4}{|c|}{ Dataset 1: Escarpment and tableland forests (Average count of logs ha $^{-1}$ ) } \\
\hline All logs & 15.48 & $<0.001$ & None \& Light $<$ Mod \& Heavy \\
\hline Non hollow bearing logs & 13.79 & $<0.001$ & None \& Light $<$ Mod \& Heavy \\
\hline Hollow bearing logs & 4.76 & 0.004 & Heavy>None \\
\hline Collapsed shell & 4.099 & 0.01 & Light $<$ Mod \& Heavy \\
\hline Heads and branches* & 6.11 & 0.1 & No differences \\
\hline \multicolumn{4}{|c|}{ Dataset 2: Coastal lowlands forests (Average volume logs $\mathrm{m}^{3} \mathrm{ha}^{-1}$ ) } \\
\hline All logs & 4.25 & 0.017 & Heavy $>$ None \\
\hline Non hollow bearing logs & 8.23 & $<0.001$ & Heavy $>$ None \\
\hline Hollow bearing logs & 2.58 & 0.08 & No differences \\
\hline Collapsed shell $^{\star}$ & 0.27 & 0.876 & No differences \\
\hline Small logs ( $15-30 \mathrm{~cm}$ diameter) & 8.405 & $<0.001$ & Heavy > Light \& None \\
\hline $\begin{array}{l}\text { Medium logs }(31-50 \mathrm{~cm} \\
\text { diameter) }\end{array}$ & 8.613 & $<0.001$ & Heavy \& Light $>$ None \\
\hline Large logs $(>51 \mathrm{~cm} \text { diameter })^{*}$ & 1.55 & 0.462 & No differences \\
\hline \multicolumn{4}{|c|}{ Dataset 2: Dissected ranges forests (Average volume logs $\mathrm{m}^{3} h \mathrm{~h}^{-1}$ ) } \\
\hline All logs & 0.72 & 0.49 & No differences \\
\hline Non hollow bearing logs* & 2.26 & 0.32 & No differences \\
\hline Hollow bearing logs* & 1.03 & 0.60 & No differences \\
\hline Collapsed shell $^{*}$ & 0.96 & 0.62 & No differences \\
\hline $\begin{array}{l}\text { Small logs }(15-30 \mathrm{~cm} \\
\text { diameter })^{*}\end{array}$ & 5.51 & 0.06 & Trend for > in Heavy \\
\hline $\begin{array}{l}\text { Medium logs }(31-50 \mathrm{~cm} \\
\text { diameter })^{\star}\end{array}$ & 5.80 & 0.06 & Trend for > in Heavy \\
\hline Large logs $(>51 \mathrm{~cm} \text { diameter })^{*}$ & 2.36 & 0.31 & No differences \\
\hline
\end{tabular}

${ }^{*}$ Kruskal-Wallis test, $\mathrm{H}$ statistic

662 Fig 1: Count of logs per ha ( $>30 \mathrm{~cm}$ diameter) and a) forest type and b) harvest intensity in 663 escarpment and tableland forests from the Dorrigo area (Dataset 1); and volume of logs (>15 cm 664 diameter $\mathrm{m}^{3} \mathrm{ha}^{-1}$ ) and c) forest type and d) harvest intensity in coastal and dissected ranges forests 665 from the Red Rock and Washpool areas (Dataset 2). Harvest intensity was scored separately in each 666 dataset, as detailed in Supplementary Table 1. Black dots represent average ( \pm standard error) total 667 log count or volume. Stacked bars show the different components of CWD: hollow and non-hollow 668 bearing; heads and branches; collapsed shells. Dataset 1 and Dataset 2 are displayed separately, 669 where the two study areas within Dataset 2 were analysed separately here (Coastal lowlands and 670 Dissected ranges). Differences between forest types was assessed for total log count (Dataset 1) or 
671 volume (Dataset 2) only. Differences between forest types were not examined in the dissected ranges

672 study area (Dataset 2) due to sampling bias towards wet sclerophyll. ${ }^{*} \mathrm{P}<0.05$; ${ }^{* *} \mathrm{P}<0.01$; ${ }^{* * *} \mathrm{P}<$

$6730.001 ; n s=$ no significant difference. GDS = Grassy dry sclerophyll forest; DSS = Dry sclerophyll

674 shrub/grass forest. $\dagger=$ result for the coastal lowlands study area (Dataset 2 ). $H=$ heavy; $M=$

675 moderate; $\mathrm{L}=$ light; $\mathrm{N}=$ none.

677 Fig 2: Estimated effect (blue line) and 95\% confidence intervals (grey shading) of environmental 678 variables on log abundance (logs ha ${ }^{-1}$ ) in the escarpment and tablelands forests from the Dorrigo area 679 (Dataset 1), for a) all harvested and unharvested sites; and b) harvested sites only. Forest type refers 680 to dry (D), wet (W) and rainforest (R) types. Harvest activities were coded as absent (0) or present (1) 681 in models of all sites. Topography includes:1) Summit; 2) Crest; 3) Saddle; 4) Upper slope; 5) Mid 682 slope; 6) Lower slope; 7) Simple slope; 8) Flat; 9) Alluvial; 10) Minor gully; 11) Creek; 12) Swamp 683

684 Fig 3: Estimated effect (blue line) and 95\% confidence intervals (grey shading) on log volume ( $\mathrm{m}^{3}$ ha $685^{1}$ ) in the coastal lowland and dissected ranges forests from the Red Rock and Washpool areas, 686 (Dataset 2) for a) all harvested and unharvested sites; and b) harvested sites only. Harvest activities 687 were coded as absent (0) or present (1) in models of all sites. Topography includes: R) Ridge; $U$ ) 688 Upper slope; M) Mid slope; L) Lower slope; and G) Gully.

689

690

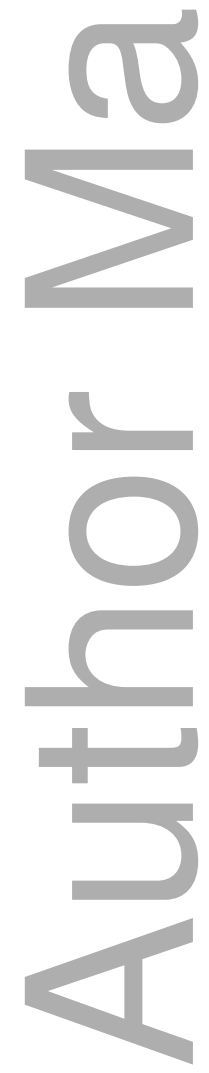

This article is protected by copyright. All rights reserved 


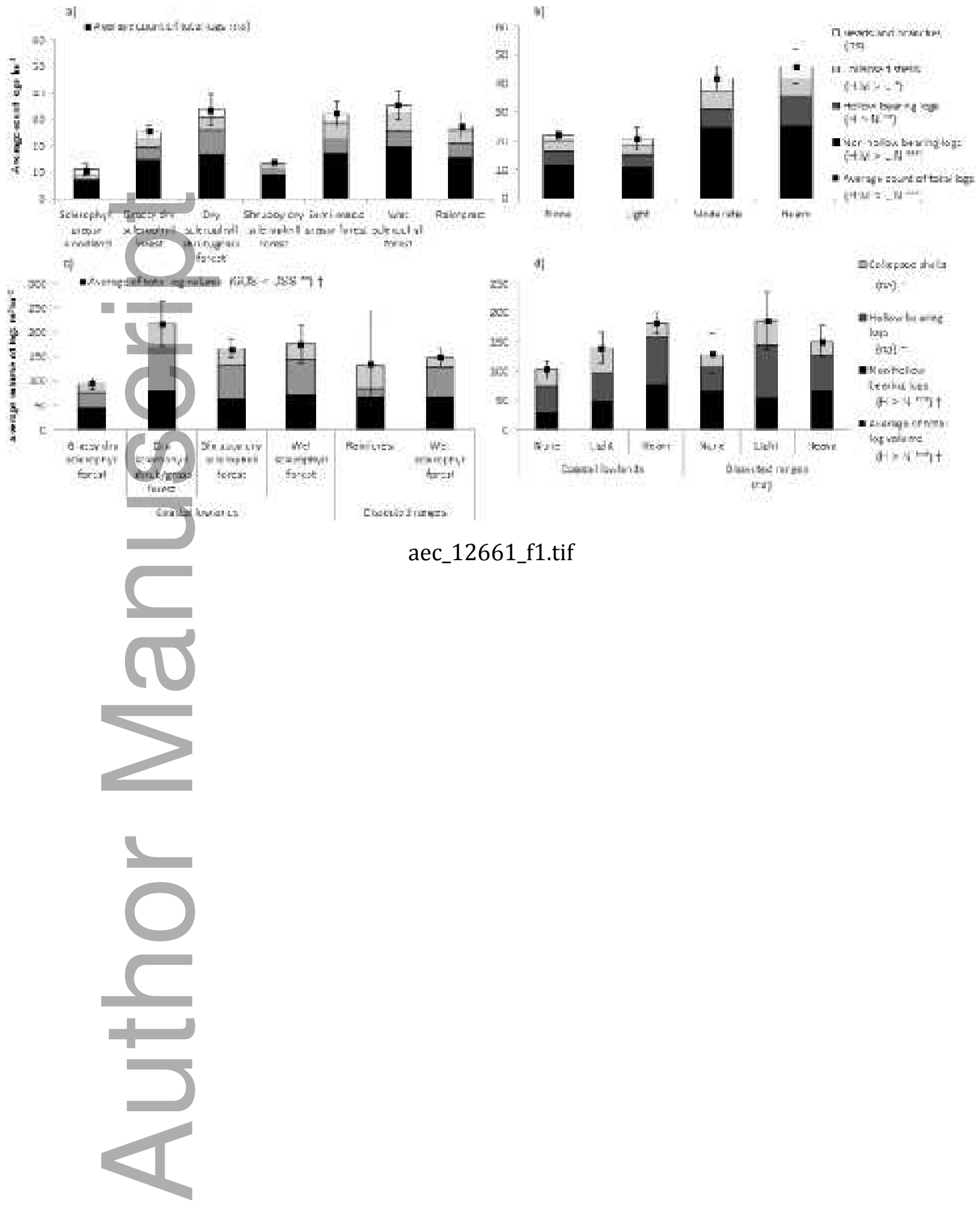



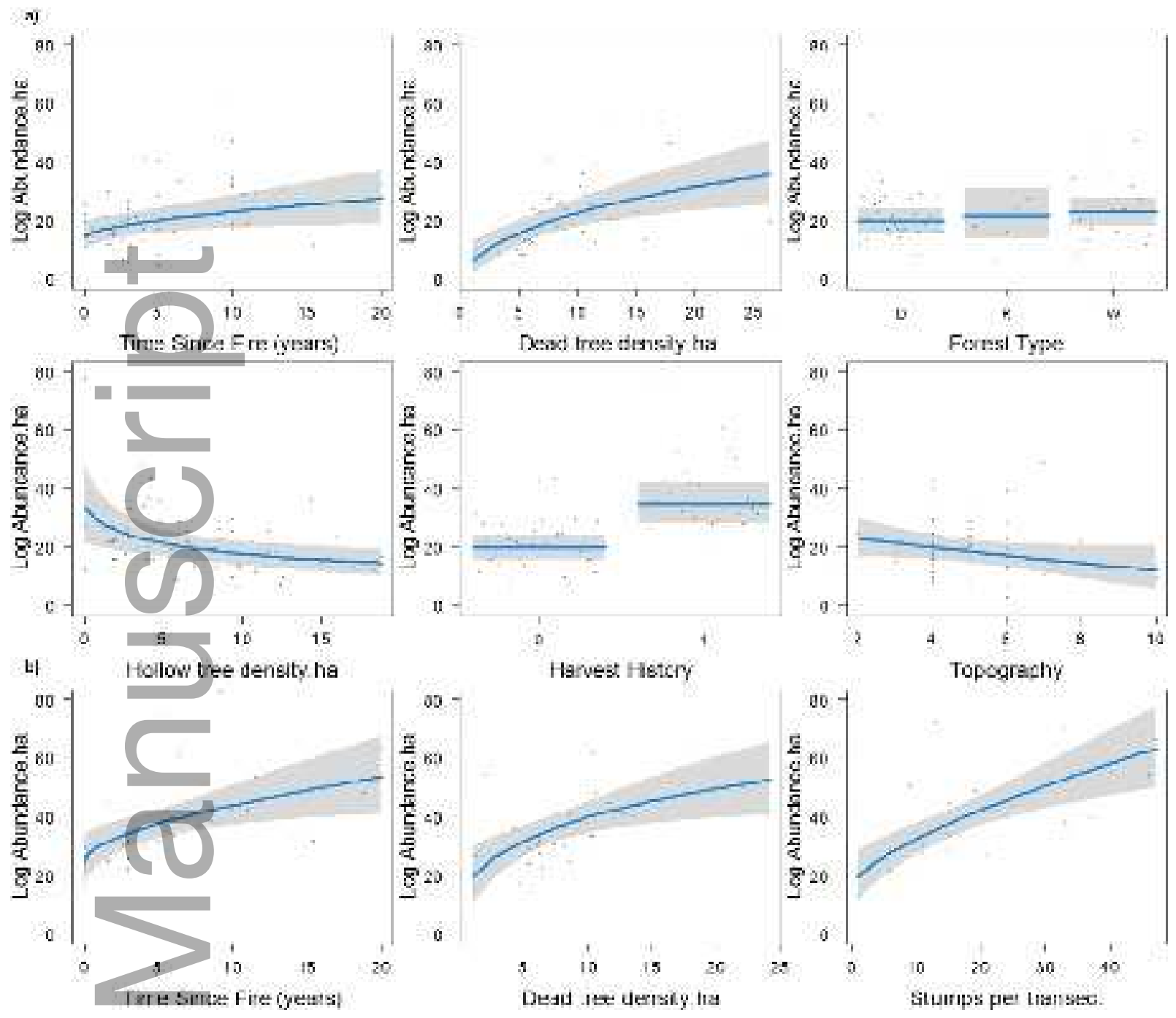

aec_12661_f2.tif

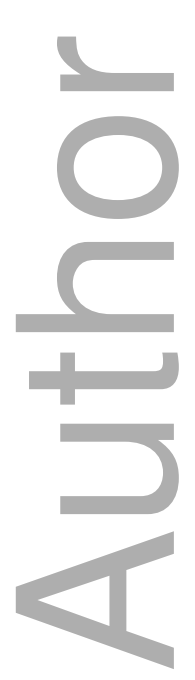



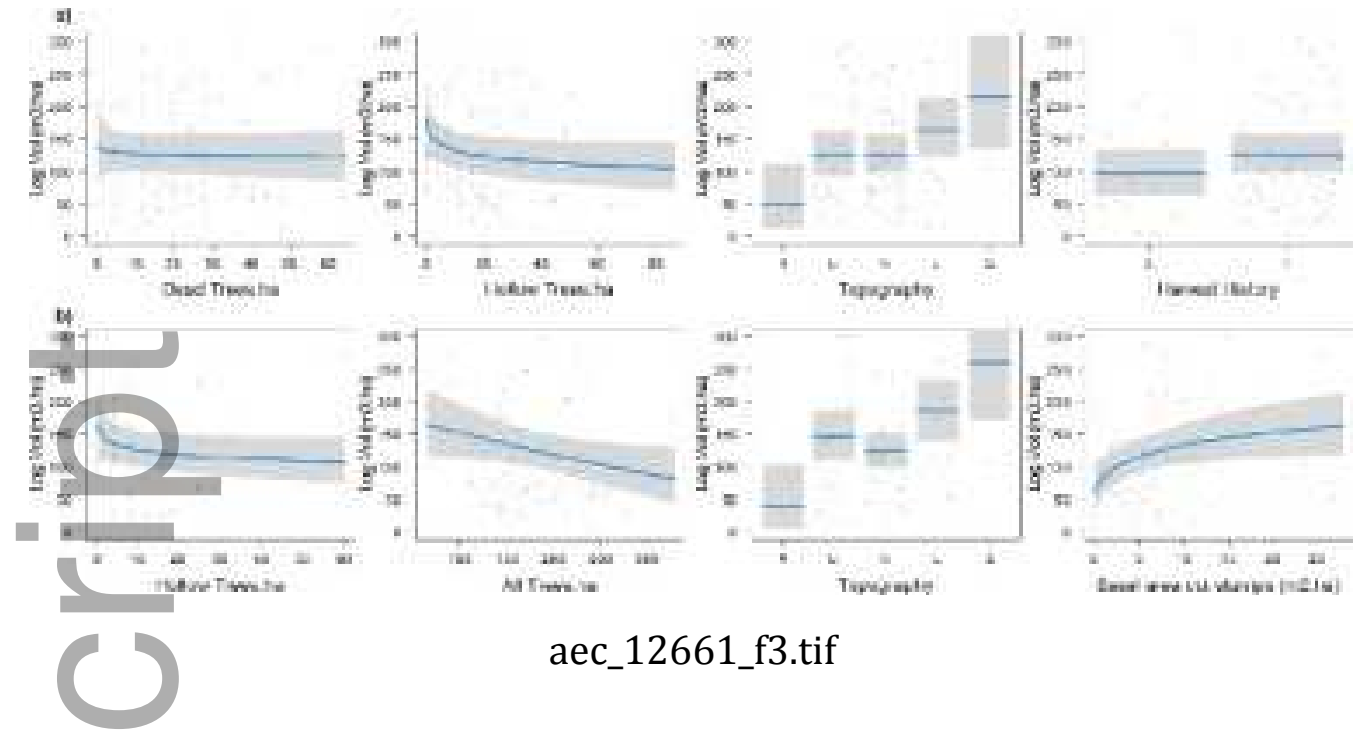

aec_12661_f3.tif
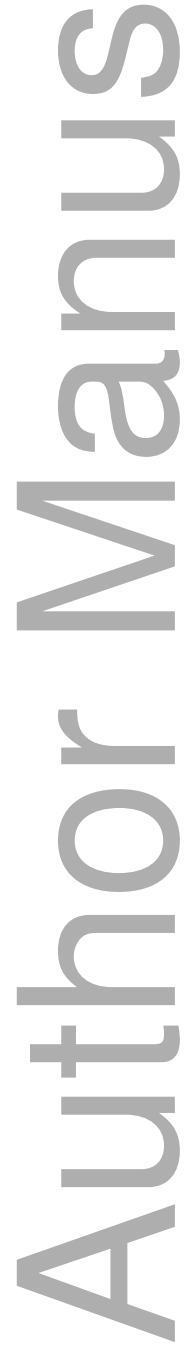


\section{University Library}

\section{- M M N E R VA A gateway to Melbourne's research publications}

Minerva Access is the Institutional Repository of The University of Melbourne

Author/s:

Threlfall, CG;Law, BS;Peacock, RJ

Title:

Benchmarks and predictors of coarse woody debris in native forests of eastern Australia

Date:

2019-02-01

Citation:

Threlfall, C. G., Law, B. S. \& Peacock, R. J. (2019). Benchmarks and predictors of coarse woody debris in native forests of eastern Australia. AUSTRAL ECOLOGY, 44 (1), pp.138-150. https://doi.org/10.1111/aec.12661.

Persistent Link:

http://hdl.handle.net/11343/284495 